\title{
Increased training volume improves bone density and cortical area in adolescent football players
}

\begin{abstract}
Habitual football participation has been shown to be osteogenic, although the specific volume of football participation required to cause bone adaptations are not well established. The aim of the present study is to investigate tibial bone adaptations in response to 12 weeks of increased training volume in elite adolescents who are already accustomed to irregular impact training.Ninety-nine male adolescent elite footballers (age $16 \pm 0 \mathrm{y}$; height $1.76 \pm 0.66 \mathrm{~m}$; body mass $70.2 \pm 8.3 \mathrm{~kg}$ ) participated. Tibial scans were performed using peripheral quantitative computed tomography immediately before and 12 weeks after an increase in football training volume. Scans were obtained at $4 \%, 14 \%, 38 \%$ and $66 \%$ of tibial length. Trabecular density $\left(\mathrm{mg} / \mathrm{cm}^{3}\right)$, cortical density $\left(\mathrm{mg} / \mathrm{cm}^{3}\right)$, cross-sectional area, cortical area $\left(\mathrm{mm}^{2}\right)$, cortical thickness $(\mathrm{mm})$ and strength strain index $\left(\mathrm{mm}^{3}\right)$ were assessed. Trabecular $(4 \%)$ and cortical density $(14 \%, 38 \%)$, cortical cross-sectional area $(14 \%, 38 \%)$, total cross-sectional area $(66 \%)$, cortical thickness $(14 \%, 38 \%)$ and strength strain index $(14 \%, 38 \%)$ increased following 12 weeks of augmented volume training $(\mathrm{P}<0.05)$.Increased density of trabecular and cortical compartments and cortical thickening were shown following an increased volume of training. These adaptive responses may have been enhanced by the adolescent status of the cohort, supporting the role of early exercise interventions in improving bone strength.
\end{abstract}




\section{Introduction}

Bone is a dynamic tissue that is continually in a state of remodelling in order to allow for adequate adaptations in response to the stresses placed upon it [27]. Bone strength and resistance to fracture are multi-factorial and are resultant from aspects of bone geometry as well as bone mineral density (BMD). Increased fracture risk can be caused by deterioration in bone strength and disturbances in bone remodelling [17]. Cross-sectional studies support an association between areal BMD and sports that require irregular impacts in recreationally active cohorts [5, 13, 14]. Although these studies are of important in furthering our understanding of the relationship between physical activity and bone health, the sole use of areal BMD as a predictor of bone health limits the applicability and reliability of these findings for the determination of bone strength, given that areal BMD is suggested to only explain around $60 \%$ of the variance in bone strength [9]. Currently our knowledge of the effects of participation in irregular impact sport on bone health are limited by the fact that the majority of studies rely on bone mineral content and areal BMD as predictors of bone strength $[5,10,13,16]$ or compare populations at a single time point $[5,10,19]$. Another limitation with cross sectional studies is the risk of sport selection bias and, therefore a cause and effect relationship cannot be determined.

Habitual mechanical loading during pre-pubertal and pubertal stages has consistently been associated with greater areal BMD, periosteal circumference [11, 15], bone mass [22] and cortical cross-sectional area [2]. Bone accrual as a result of physical activity during growth periods was preserved into adulthood, even when regular exercise was discontinued [15, 21], thus making the adolescent period important in investigations related to long-term bone health and the osteogenic benefits of exercise and athletic performance. 
Athletes participating in sports that necessitate frequent, high magnitude loading suffer a relatively high rate of bone injuries (Stress fracture period prevalence $24.9 \%$ in 518 elite athletes; [23]). possibly due to the magnitude of mechanical load undertaken. Repeated high magnitude mechanical loading can cause damage to the micro-architecture of bone [2]. As bone remodelling increases to repair the inflicted micro-damage, cortical porosity of the bone increases and density decreases, ultimately causing site-specific weaknesses [26]. Factors such as rapid increases in training volume have been implicated in negative effects on bone characteristics [2]. Irregular impact sport eliciting both positive and negative changes to bone structural properties are likely to involve the mode, intensity and volume of exercise, as well as various intrinsic and extrinsic factors [2]. There is a lack of studies investigating specific aspects of training that are associated with bone structural characteristics since most interventions involve unaccustomed activity and/or increased exercise volume, magnitude of loading, intensity and duration simultaneously [3, 4].

In the majority of professional football clubs worldwide, players at the age of 16 years' experience an increase in training volume when they graduate from part-time to full-time training, while the type of training is unchanged. Assessing bone characteristics at the start of full-time training offers opportunity to observe the response to an increase in training volume in a cohort accustomed to the type and intensity of training. The aim of the current study was to investigate tibial bone adaptions in response to 12 weeks of increased training volume in elite adolescent football players transitioning from part to full-time training. A secondary aim was to quantify changes in bone over 12 weeks in adolescent footballers with maintained training volume. 


\section{Methods}

\section{Participants}

First year full-time academy footballers $(n=117)$ were recruited through previously established relationships with Nottingham Trent University and by word of mouth from five full-time football academies to form the Bone Adaptation in Academy Footballers cohort (BAAF) . Participants were deemed eligible for the study if they were contracted to their football club on a full-time basis, aged 16 years, injury free, not currently taking any medication that influenced bone metabolism and had not received a joint replacement or prostheses. After reading the participant information sheet and having the opportunity to ask questions, participants signed a statement of informed consent, completed a pre-scan screening form and completed a health screen questionnaire. Participants detailed their playing position, the age at which they first played competitive football and the amount of hours they spent training prior to full-time academy enrolment. The study conformed to Ionising Radiation Regulations and was approved by the National Health Service Research Ethics Committee. The study was also conducted in accordance with international standards $[6]$.

Following study completion, the coach and/or physiotherapist of the football club provided information related to each individual's training time, which included time missed as a result of injury for the previous 12 weeks. Of the 117 football players assessed for eligibility, six players were under the age of 16 years, 12 players who received an initial scan were lost to the follow-up scan for a variety of reasons (Figure 1), leaving a cohort of $n=99$ who completed both scans. There were no significant differences in baseline characteristics 
between the cohort with completed datasets and the 12 players withdrawn from the study $(\mathrm{P}>0.05)$.

Procedures

Academy footballers were tested for baseline variables during the first week of pre-season training including height, body mass and bone characteristics using peripheral quantitative computed tomography (pQCT) (XCT2000L, Stratec Medizintechnik, Pforzheim, Germany). Footballers then conducted 12 weeks football-specific training of comparable type to the activities conducted before the baseline scan. All training was conducted and supervised by qualified coaches at respective clubs. After 12 weeks the measurements conducted at baseline were repeated.

Height (Stadiometer, Seca, Hamburg, Germany) and body mass (Seca, Birmingham, U.K.) were recorded with participants wearing minimal clothing.

Academy footballers that were deemed of a suitable standard by their club graduated through the academy to become first year scholars. Although habitually accustomed to football training and match play as part of their representation of the academy in younger age groups, the start of the study was timed to coincide with their first experience of full-time training. The training sessions (typically 1-2 hours) consisted of high intensity running drills, smallsided games and technique based drills.

pQCT scans were taken of the dominant leg (defined as the leg that the participant most comfortably kicked a ball with). All scans were performed by the same operator, before scanning commenced, the scanner was cross-calibrated using phantoms of known density in accordance with manufacturer guidelines. pQCT has previously been shown to provide a reliable measurement of bone characteristics in humans by our wider research group [Izard et 
al., 2016] and others [1]. The participants' tibial length was measured to the nearest $1 \mathrm{~mm}$, determined as the midpoint of the medial malleolus to the medial aspect of the tibial plateau. The participants leg was then placed in the scanner with their foot secured by a purpose built attachment. The leg was aligned with use of an integral laser and a clamp was placed to the knee to reduce movement, with the participant instructed to remain as still as possible for the duration of the scan. Initially, a preliminary reference point locating scout-view scan was performed in the frontal plane to confirm the location of the middle of the distal end plate, which would act as a positioning line. Sectional images, were then obtained at $4 \%, 14 \%, 38 \%$ and $66 \%$ from the positioning line with a voxel size set at $0.5 \mathrm{~mm}$ and a slice thickness of $2.5 \mathrm{~mm}$ for all measurements. A contour mode, with a threshold of $180 \mathrm{mg} \cdot \mathrm{cm}^{-3}$, was used to separate soft tissue and bone. To analyse trabecular bone, a constant default threshold of $711 \mathrm{mg} \cdot \mathrm{cm}^{-3}$ was used to identify and remove cortical bone. The integral XCT2000L software (version 6.20A) was used to analyse the images.

If any movement artefacts were present following the scan, the image was classed as invalid and a repeat measure was performed. If an artefact was present in the second image the participant was removed from the study in line with the radiation exposure guidelines.

The following measures were analysed: $4 \%$ : total cross sectional area $\left(\mathrm{CSA}, \mathrm{mm}^{2}\right)$ and trabecular BMD $\left(\mathrm{mg} \cdot \mathrm{cm}^{-3}\right) .14 \%$ and $38 \%: \mathrm{CSA},\left(\mathrm{mm}^{2}\right)$, cortical CSA $\left(\mathrm{mm}^{2}\right)$, cortical BMD $\left(\mathrm{mg} \cdot \mathrm{cm}^{-3}\right)$, cortical thickness $(\mathrm{mm})$, periosteal circumference $(\mathrm{mm})$ and stress strain index $\left(\mathrm{SSI}, \mathrm{mm}^{-3}\right) .66 \%$ : Total CSA, $\left(\mathrm{mm}^{2}\right)$ and cortical BMD $\left(\mathrm{mg} \cdot \mathrm{cm}^{-3}\right)$.

\section{Secondary Study}

After the experimental study was completed a secondary study was conducted. The aim of the secondary study was to quantify changes in bone over 12 weeks in adolescent footballers 
with maintained training volume, not to compare the cohort from the secondary study to the main experimental cohort.

Participants

Recreationally active (played football habitually, as part of a non-elite club) footballers aged 16 years old $(n=13)$ were recruited (participant characteristics are shown in supplementary table 1) from a college with links to Nottingham Trent University. The study conformed to Ionising Radiation (Medical Exposure) Regulations and was approved by the National Health Service Research Ethics Committee.

Procedures

Recreationally active footballers were tested for baseline variables (June) including height, body mass and bone characteristics using pQCT during their competitive season. Footballers then continued with their football-specific training for a further 12 weeks. All training was conducted and supervised by qualified coaches at the footballers college. After 12 weeks (September) the measurements conducted at baseline were repeated. Height and body mass were recorded in the same way as the experimental study.

No intervention was undertaken, recreationally active footballers maintained their pre-study training volume for the duration of the study. The training sessions consisted of high intensity running drills, small-sided games and technique based drills. The training status of the recreationally active footballers was reported by their coach. pQCT measurements were conducted in the same way as the experimental study.

Statistical analysis

All data are presented as mean \pm 1 SD. Data were tested for normality using the Shapiro-Wilk test. Normally distributed data were compared using paired sample t-tests to assess 
participant characteristics and bone characteristics at baseline and following the training period. A significance level was set at $\mathrm{P}<0.05$ and $\mathrm{P}$ values were reported in two levels $(\mathrm{P}<0.05$ and $\mathrm{P}<0.01)$. All statistical analysis was performed with Statistical Package for the Social Sciences (SPSS) version 22.0 (SPSS, Inc., Chicago, IL, USA).

\section{Results}

Participant characteristics

Participants were of different ethnicities (69 Caucasian, 14 Caucasian/black dual heritage, 8 black African, 7 black Caribbean, and 1 Asian) and composed of differing playing positions (42 midfielders, 28 defenders, 20 forwards and 9 goalkeepers).

Body mass significantly increased post intervention, although only by a mean of $1 \mathrm{~kg}$. Tibial length did not significantly change (Table 1). The number of training hours per week significantly increased (106\%) following full-time academy induction.

Bone Response to Increased Training

$4 \%$ of tibial length

Trabecular density significantly increased following 12 weeks of increased training volume $(\mathrm{P}<0.05)$. No change was shown in total CSA $(\mathrm{P}>0.05)$ (Table 2$)$.

$14 \%$ and $38 \%$ of tibial length

Cortical density and CSA all increased following 12 weeks of increased training volume $(\mathrm{P}<0.01)$. Cortical thickness also increased at the $14 \%(\mathrm{P}<0.05)$ and $38 \%(\mathrm{P}<0.01)$ sites. Estimated bone strength (SSI) increased following training (14\% site $\mathrm{P}<0.05 ; 38 \%$ site $\mathrm{P}<0.01)$. No change was shown in either total CSA or periosteal circumference $(\mathrm{P}>0.05)$ (Table 2). 
$66 \%$ of tibial length

Cortical density significantly increased following 12 weeks of increased training volume $(\mathrm{P}<0.05)$. No change was shown in total CSA $(\mathrm{P}>0.05)$ (Table 2$)$.

Significant increases in SSI (38\%), trabecular density (4\%), cortical density (14\%; 38\%) and cortical thickness (14\%) were still present after adjusting for changes in body weight $(\mathrm{P}<0.05)$.

Secondary study results

Bone characteristics in the recreationally active footballers ranged from a decrease of $0.6 \%$ to an increase of $4.4 \%$ but weren't statistically significant $(\mathrm{P}>0.05)$ (supplementary table 2$)$. No changes in bone characteristics were shown after adjusting for changes in body weight $(\mathrm{P}>0.05)$.

\section{Discussion}

This is the first known study to show osteogenic bone adaptations in response to 12 weeks of increased training in a population of elite adolescent footballers who were already accustomed to football specific training. Increases in trabecular density, SSI and cortical density, thickness and CSA at various tibial sites were shown in response to an unaccustomed increase in training volume. The increases shown in cortical and trabecular density of elite adolescent footballers may signify an increase in primary bone mineralisation occurring during the bone formation process [20], while increases in cortical CSA may have resulted from an increase in endocortical and intracortical remodelling [20] caused by an increase in training volume. 
The increase shown in bone characteristics at various tibial sites in the present study is suggested to be associated with an increase in training volume; the type of training did not change. We hypothesise that bone adapts to an increase in training volume because of the need to prevent structural fatigue with the new additional loading. Increased cortical CSA and thickness improves bone strength by increasing resistance to bending as bone is placed at an increased distance from the neutral axis. Osteogenic benefits are likely to be achieved at forces close to the microdamage threshold [7], which may heighten stress fracture injury risk in some individuals As low bone mineral density (Wentz et al., 2012) and lower cortical area (Popp et al., 2009) have been associated with the development of stress fracture injury, this may explain the relatively high prevalence of stress fracture injury as a result of football participation [23].

The bone characteristics shown to increase in response to increased training volume over 12 weeks are the same characteristics that have been shown to be higher in habitual, non-elite footballers when compared to control populations in cross-sectional studies (trabecular density [16]; SSI [19]; cortical thickness and CSA [25]). Increased training volume resulted in an increase in trabecular density at the $4 \%$ tibial site in the present study, increased trabecular density has also be shown in response to participation unaccustomed exercise intervention consisting of an increase in volume and intensity of exercise [4]. These studies suggest that increased training volume and an increase in the frequency of high magnitude and irregularity of impacts, which is thought to be important for bone accrual [24], is an important factor in the osteogenic effects of exercise. 
An increase in cortical density shown following 12 weeks of football specific training is in contrast to previous cross-sectional findings showing lower cortical density in habitual football players compared to sedentary controls [16]. Lower density may be attributed to an increase in bone remodelling as a result of micro-damage caused by the high loading that weight-bearing exercise elicits [26]. The longitudinal design of the present study in an elite, homogenous (participants were all of the same age) cohort suggests that an increased volume of football training increases cortical density. As previous cohorts were older and of a nonelite status this might suggest that cortical density responds differently to training in an adolescent cohort and/or there is a greater amount of variability in the intensity and mode of exercise non-elite athletes undertake.

There is a relatively high prevalence of tibial stress fracture injury in athletes competing in weight-bearing sports during adolescence [23], probably due to optimal osteogenesis occurring very close to the microdamage threshold [7]. Our findings support the osteogenic effects of football participation, but future longer-duration longitudinal studies are required to assess the incidence of stress fracture injury and explore individual responses to football specific loading. Adolescent basketball players exposed to multi-directional movement experienced decreased stress fracture injury incidence compared to non-basketball players [21]. It has also been shown that higher bone mass and geometry are associated with greater habitual physical activity in adolescence [8]. While these findings suggest an association between physical activity and bone characteristics in adolescence, specific details related to the type, volume and duration of exercise are imprecise given that participant activity levels were only determined via questionnaire or by hip based accelerometry (data were collected for 7 days and extrapolated to reflect habitual activity). 
The present study benefits from a large cohort, but ethnicity and playing position were not standardised. The differing physical demands of each playing position may lead to differing bone characteristics but as the majority of academy players played in numerous positions this is unlikely to have influenced the current findings. Participants were of equivalent age, were all male, had similar lifetime and recent training histories and the environment was relatively well controlled (ie., the time of year the scans took place and dietary habits; participants ate two meals per day five times per week at their respective club). Typically, breakfast consisted of a buffet that included porridge, toast, cereals, yogurt and a selection of fruit. Lunch consisted of chicken or grilled fish with rice or pasta and the option of a side salad. Water and fruit juice was also offered). Factors, such as intensity of exercise training and dietary habits outside of the players' football club could also have influenced the findings shown, but as intensity is difficult to objectively quantify and no feasible method exists to accurately record diet over a period of 12 weeks in a large group of participants (Schatzkin et al., 2003).Maturation may influence bone adaptations in adolescents [12], although no changes in tibial length occurred within the present study timeframe, meaning we are confident that the same region of the tibia was scanned at both time points. No changes in bone characteristics were shown in recreationally active adolescent footballers assessed in the secondary study, who maintained their training volume over an equivalent 12-week period. Previous research also shows that adolescences bone characteristics were unaffected by moderate or light physical activity [18], thus giving further confidence that the changes shown in academy footballers were as a result of increased training volume. It would have been advantageous to compare the findings of the primary study to a control group. However, to recruit an adequate control group, age matched academy footballers that were accustomed to the specific type of training would have to maintain their training volume for the duration of the trial. It would be 
impractical and unethical to recruit elite footballers and advise them to maintain current training practices while their counterparts are increasing their training volume, since there would be a potential issue over their future selection.

These findings show the tibia adapts to an increased volume of football training by mineralising trabecular and cortical compartments and cortical thickening. These data support the use of increased football specific training volume as a method in which to cause osteogenic adaptations in adolescent footballers. These adaptive responses may have been enhanced by the adolescent status of the academy football players, supporting the role of early exercise interventions in improving bone strength.

\section{References}

1. Ashe MC, Liu-Ambrose T, Khan KM, White N, McKay HA. Optimizing results from pQCT: reliability of operator-dependent pQCT variables in cadavers and humans with low bone mass. J Clin Densitom. 2005; 8:335-340.

2. Bennell K, Matheson G, Meeuwisse W, Brukner P. Risk factors for stress fractures. Sports Med, 1999; 28:91-122.

3. Dhamrait SS, James L, Brull DJ, Myerson S, Hawe E, Pennell DJ, Humphries SE, Haddad F. Montgomery HE. Cortical bone resorption during exercise is interleukin-6 genotype-dependent. Eur J Appl Physiol. 2003;89: 21-25. 
4. Evans RK, Negus CH, Centi AJ, Spiering BA, Kraemer, WJ, Nindl BC. Peripheral QCT sector analysis reveals early exercise-induced increases in tibial bone mineral density. $\mathrm{J}$ Musculoskelet Neuronal Interact. 2012; 12:155-164.

5. Ferry B, Duclos M, Burt L, Therre P, Le Gall F, Jaffré C. Courteix D. Bone geometry and strength adaptations to physical constraints inherent in different sports: comparison between elite female soccer players and swimmers. J Bone Miner Metab. 2011;29 :342-351.

6. Harriss DJ, Atkinson G. Ethical standards in sport and exercise science research: 2016 update. Int J Sports Med 2015; 36: 1121-1124.

7. Hsieh YF, Robling AG, Ambrosius WT, Burr DB, Turner CH. Mechanical loading of diaphyseal bone in vivo: the strain threshold for an osteogenic response varies with location. J Bone Miner Res. 2001;16:2291-2297.

8. Janz KF, Letuchy EM, Burns TL, Eichenberger Gilmore JM, Torner JC, Levy SM. Objectively measured physical activity trajectories predict adolescent bone strength: Iowa Bone Development Study.Br J Sports Med. 2014;48:1032-1036.

9. Keen RW. Effects of lifestyle interventions on bone health. Lancet. 1999;354:19231924

10. Krustrup P, Aagaard P, Nybo L, Petersen J, Mohr M, Bangsbo J. Recreational football as a health promoting activity: a topical review. Scand J Med Sci Sports. 2010;20: 1-13.

11. Lorentzon M, Mellström, D, Ohlsson, C. Association of amount of physical activity with cortical bone size and trabecular volumetric BMD in young adult men: the GOOD study. J Bone Miner Res. 2005;20:1936-1943.

12. Loud KJ, Gordon CM. Adolescent bone health. Arch Pediatr Adolesc Med. 2006; 160:102-132.

13. Morgan A, Weiss Jarrett J. Markers of bone turnover across a competitive season in female athletes: a preliminary investigation. J Sports Med Phys Fitness. 2011;51: 515-524.

14. Mudd LM, Fornetti W, Pivarnik JM. Bone Mineral Density Comparisons Among College Female Athletes. Clin J Sport Med. 2006;16:440.

15. Nilsson M, Ohlsson C, Mellström, D, Lorentzon M. Previous sport activity during childhood and adolescence is associated with increased cortical bone size in young adult men. J Bone Miner Res. 2009;24:125-133.

16. Nilsson M, Ohlsson C, Odén A, Mellström D, Lorentzon M. Increased physical activity is associated with enhanced development of peak bone mass in men: A five - year longitudinal study. J Bone Miner Res.2012; 27:1206-1214. 
17. Nguyen, N.D., Frost, S., Center, J.R., Eisman, J.A. and Nguyen, T., Development of a nomogram for individualizing hip fracture risk in men and women. Osteoporos Int. 2007; 18:1109-1117.

18. Sayers A, Mattocks C, Deere K, Ness A, Riddoch C, and Tobias JH. Habitual levels of vigorous, but not moderate or light, physical activity is positively related to cortical bone mass in adolescents. J Clin Endocrinol Metab. 2011 96:E793-802.

19. Schipilow J, Macdonald H, Liphardt A, Kan M, Boyd S. Bone micro-architecture, estimated bone strength, and the muscle-bone interaction in elite athletes: An HR-pQCT study. Bone. 2013; 56: 281-289.

20. Seeman E, Delams PD. Bone Quality - The material and structural basis of bone strength and fragility. The New England Journal of Medicine. 2006;354,2250-2261.

21. Tenforde AS, Fredericson M. 2011. Influence of sports participation on bone health in the young athlete: a review of the literature. PM R. 2011; 3:861-867.

22. Tobias JH, Steer CD, Mattocks CG, Riddoch C, Ness, AR. Habitual Levels of Physical Activity Influence Bone Mass in 11 - Year - Old Children From the United Kingdom: Findings From a Large Population - Based Cohort. J Bone Miner Res. 2007; 22:101-109.

23. Varley I, Hughes DC, Greeves JP, Stellingwerff T, Ranson C, Fraser WD, Sale C. RANK/RANKL/OPG pathway: Genetic associations with stress fracture period prevalence in elite athletes. Bone. 2015;71:131-136.

24. Vicente-Rodriguez G, Jimenez-Ramirez J, Ara I, Serrano-Sanchez J, Dorado C, Calbet J. Enhanced bone mass and physical fitness in prepubescent footballers. Bone. 2003;33:853-859.

25. Weidauer L, Minett M, Negus C, Binkley T, Vukovich M, Wey H, Specker B. Oddimpact loading results in increased cortical area and moments of inertia in collegiate athletes. Eur J Appl Physiol. 2014;114:1429-1438.

26. Wilks DC, Winwood K, Gilliver S, Kwiet A, Chatfield M, Michaelis I, Sun L, Ferretti JL, Sargeant, AJ. Felsenberg D. Bone mass and geometry of the tibia and the radius of master sprinters, middle and long distance runners, race-walkers and sedentary control participants: a pQCT study. Bone. 2009;45:91-97.

27. Zaidi, M., Skeletal remodeling in health and disease. Nature Medicine. 2007; 13 (7), 791-801.

\section{List of Figures and Tables}

Figure 1. Academy footballers assessed and analysed depicted in a consort chart. 
Table 1. Characteristics of academy footballers analysed pre and post 12 weeks of increased training volume. Values are mean $( \pm 1 \mathrm{SD})$ and $* *$ denotes a significant difference $(\mathrm{P}<0.01)$.

Table 2. Bone phenotypes (mean $\pm 1 \mathrm{SD}$ ) at $4 \%, 14 \%, 38 \%$ and $66 \%$ of the tibia measured before and after 12 weeks of increased volume football specific training in elite footballers. $(\mathrm{CSA})=$ cross sectional area. $*$ was used to denote significance $\mathrm{P}<0.05 ; * *$ was used to denote significance $\mathrm{P}<0.01$. 


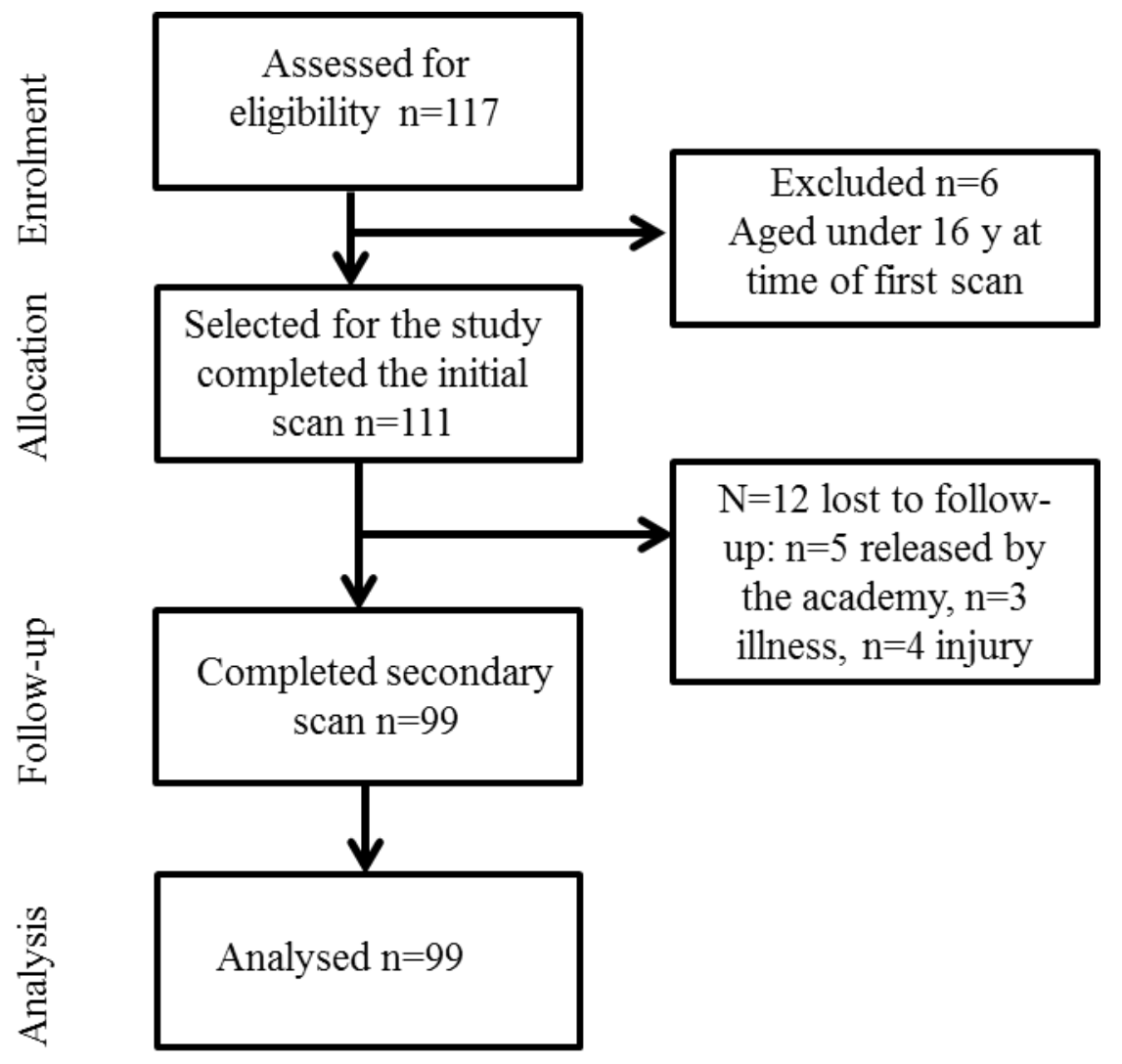

Figure 1. Academy footballers assessed and analysed depicted in a consort chart.

Table 1. Characteristics of academy footballers analysed pre and post 12 weeks of increased training volume. Values are mean $( \pm 1 \mathrm{SD})$ and $* *$ denotes a significant difference $(\mathrm{P}<0.01)$.

\begin{tabular}{lll}
\hline Characteristics $(\mathrm{n}=99)$ & $\begin{array}{l}\text { Pre increased } \\
\text { training } \\
\text { volume }\end{array}$ & $\begin{array}{l}\text { Post } \\
\text { increased } \\
\text { training } \\
\text { volume }\end{array}$ \\
\hline Height $(\mathrm{m})$ & $1.76 \pm 0.56$ & $1.77 \pm 0.62$ \\
Body Mass $(\mathrm{kg})$ & $70.1 \pm 8.5$ & $71.4 \pm 8.7^{* *}$ \\
Tibia length (mm) & $387.3 \pm 21.3$ & $387.6 \pm 20.8$ \\
Age when first played competitively $(\mathrm{y})$ & $9.4 \pm 1.4$ & N/A \\
Training (h/wk) & $6.2 \pm 2.7$ & $11.9 \pm 1.6^{* *}$ \\
\hline
\end{tabular}


Table 2. Bone phenotypes (mean $\pm 1 \mathrm{SD})$ at $4 \%, 14 \%, 38 \%$ and $66 \%$ of the tibia measured before and after 12 weeks of increased volume football specific training in elite footballers. $(\mathrm{CSA})=$ cross sectional area. * was used to denote significance $\mathrm{P}<0.05$; ** was used to denote significance $\mathrm{P}<0.01$.

Football $n=99$

\begin{tabular}{|c|c|c|c|}
\hline Bone Phenotype & Pre & Post & $\%$ change \\
\hline \multicolumn{4}{|l|}{$4 \%$ site } \\
\hline Trabecular Density $\left(\mathrm{mg} \cdot \mathrm{cm}^{3}\right)$ & $284.2 \pm 31.1$ & $289.6 \pm 31.1 * *$ & $1.9 \uparrow$ \\
\hline Total CSA $\left(\mathrm{mm}^{2}\right)$ & $1338.3 \pm 149.7$ & $1348.2 \pm 147.2$ & $0.7 \uparrow$ \\
\hline \multicolumn{4}{|l|}{$14 \%$ site } \\
\hline Cortical Density $\left(\mathrm{mg} \cdot \mathrm{cm}^{3}\right)$ & $1057.2 \pm 34.5$ & $1066.9 \pm 32.7 * *$ & $0.9 \uparrow$ \\
\hline Total CSA $\left(\mathrm{mm}^{2}\right)$ & $570.1 \pm 80.4$ & $572.5 \pm 80.0$ & $0.4 \uparrow$ \\
\hline Cortical CSA $\left(\mathrm{mm}^{2}\right)$ & $212.2 \pm 21.1$ & $215.8 \pm 24.1 * *$ & $1.7 \uparrow$ \\
\hline Cortical Thickness (mm) & $2.85 \pm 0.32$ & $2.88 \pm 0.34^{*}$ & $1.1 \uparrow$ \\
\hline Periosteal Circumference (mm) & $84.3 \pm 5.5$ & $84.5 \pm 5.4$ & $0.2 \uparrow$ \\
\hline SSI & $2034.4 \pm 360.2$ & $2061 \pm 377.2 *$ & $1.3 \uparrow$ \\
\hline \multicolumn{4}{|l|}{$38 \%$ site } \\
\hline Cortical Density $\left(\mathrm{mg} \cdot \mathrm{cm}^{3}\right)$ & $1108.7 \pm 32.0$ & $1115.2 \pm 29.9 * *$ & $0.6 \uparrow$ \\
\hline Total CSA $\left(\mathrm{mm}^{2}\right)$ & $488.8 \pm 60.2$ & $489.4 \pm 60.1$ & $0.1 \uparrow$ \\
\hline Cortical CSA $\left(\mathrm{mm}^{2}\right)$ & $356.9 \pm 40.2$ & $361.5 \pm 40.1 * *$ & $1.3 \uparrow$ \\
\hline Cortical Thickness (mm) & $6.05 \pm 0.50$ & $6.10 \pm 0.57 * *$ & $0.8 \uparrow$ \\
\hline Periosteal Circumference (mm) & $78.0 \pm 5.1$ & $78.3 \pm 4.6$ & $0.4 \uparrow$ \\
\hline SSI & $2054.7 \pm 392.8$ & $2101.9 \pm 396.1 * *$ & $2.3 \uparrow$ \\
\hline
\end{tabular}

$66 \%$ site 
Cortical Density $\left(\mathrm{mg} \cdot \mathrm{cm}^{3}\right) \quad 1074.7 \pm 27.4 \quad 1079.9 \pm 22.1 * * \quad 0.5 \uparrow$

Total CSA $\left(\mathrm{mm}^{2}\right) \quad 9778.1 \pm 1072.5 \quad 9668.9 \pm 1081.2 \quad 1.1 \downarrow$ 